\title{
Yield Curve Modeling and Forecasting using Semiparametric Factor Dynamics
}

\author{
Wolfgang Karl Härdle* \\ Piotr Majer*
}

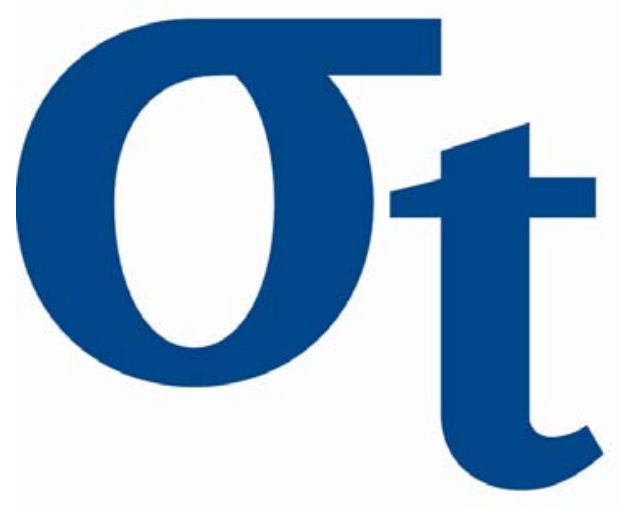

* Humboldt-Universität zu Berlin, Germany 


\title{
Yield Curve Modeling and Forecasting using
}

\section{Semiparametric Factor Dynamics*}

\author{
Wolfgang Karl Härdleł Piotr Majer
}

August 8, 2012

\begin{abstract}
Using a Dynamic Semiparametric Factor Model (DSFM) we investigate the term structure of interest rates. The proposed methodology is applied to monthly interest rates for four southern European countries: Greece, Italy, Portugal and Spain from the introduction of the Euro to the recent European sovereign-debt crisis. Analyzing this extraordinary period, we compare our approach with the standard market method - dynamic Nelson-Siegel model. Our findings show that two nonparametric factors capture the spatial structure of the yield curve for each of the bond markets separately. We attributed both factors to the slope of the yield curve. For panel term structure data, three nonparametric factors are necessary to explain $95 \%$ variation. The estimated factor loadings are unit root processes and reveal high persistency. In comparison with the benchmark model, the DSFM technique shows superior short term forecasting.

JEL classification: G12, G17, C5, C4
\end{abstract}

*The authors gratefully acknowledge financial support from the Deutsche Forschungsgemeinschaft through CRC 649 "Economic Risk".

${ }^{\dagger}$ Humboldt-Universität zu Berlin, C.A.S.E. - Center for Applied Statistics and Economics, Unter den Linden 6, 10099 Berlin, Germany

${ }^{\ddagger}$ Humboldt-Universität zu Berlin, C.A.S.E. - Center for Applied Statistics and Economics, Unter den Linden 6, 10099 Berlin, Germany 
Keywords: yield curve, term structure of interests rates, semiparametric model, factor structure, prediction

\section{Introduction}

Modeling and forecasting the term structure of interest rates are important in financial economics. Pricing financial assets and their derivatives, allocating portfolios, managing financial risk, conducting monetary policy are the essential challenges which involve interest rates and dynamic evolution of the yield curve. For that reason researchers have developed a large toolbox of models and techniques. The most popular approaches are equilibrium and no-arbitrage models. The no-arbitrage models follow the BlackScholes framework and ensure correct pricing of derivatives; the main contributions for no-arbitrage models are Hull and White (1990) and Heath et al. (1992). The equilibrium framework provides exact fits to the observed term structure Longstaff and Schwartz, 1992). However both approaches do not provide a good predictive performance, since forecasting is not the main goal of these approaches. To this end, Diebold and Li (2006) proposed the Nelson-Siegel curve with time varying parameters. The Dynamic NelsonSiegel model has gained popularity among financial market practitioners and central banks. This relatively new dynamic factor model provides a remarkably good fit to the term structure of interest rates, where the given factors of the exponential form have a standard interpretation of level, slope, and curvature. Parametric structure of Dynamic Nelson-Siegel model leads to easy estimation and displays empirical tractability. In the same spirit generalizations of the Nelson-Siegel approach were introduced by Svensson (1995) and Christensen et al. (2009). Dynamic factor models for yield curve modeling are reported to be extremely useful in practice (e.g., Federal Reserved Board Gürkaynak et al. 2010); European Central Bank (Coroneo et al., 2008)).

In this paper we go beyond the Nelson-Siegel structure by proposing a dynamic semi- 
parametric factor model. The paper's major idea is to capture the shape of the yield curve by a lower-dimensional factor representation. The latent factors are estimated non-parametrically by tensor B-splines avoiding specification issues (e.g. exponential form imposed in the Nelson-Siegel model). The choice of the B-splines series expansion is motivated by Vasicek and Fong (1982), who first implemented it in a term structure model. Since that time B-splines series has attracted much research attention and serves as flexible yield curve modeling approach (Krivobokova et al. (2006) and Bowsher and Meeks (2008)). Similarly to parametric Nelson-Siegel models and functional principal component analysis (FPCA, Ramsay and Silverman (1997)), yield curve is represented as a linear combination of latent factors. The evolution in time is driven by time-varying factor loadings (in FPCA defined as scores), which are modeled parametrically employing a multivariate autoregressive approach. The factor decomposition is obtained by the Dynamic Semiparametric Factor Model (DSFM) also analyzed in Fengler et al. (2007), Brüggemann et al. (2008) and Park et al. (2009). Accordingly, the term structure of interests rates is modeled in terms of underlying latent factors, which are defined on the time to maturity grid space and may depend on additional explanatory variables. The inclusion of additional regressors is motivated by Taylor's rule (Taylor, 1992) and was also picked up by Diebold et al. (2006), Ang and Piazzesi (2003). The main idea is to incorporate the macroeconomic activity as a determinant of the yield curve. The connection between yield curve dynamics and contemporaneous macroeconomic fundamentals is investigated in terms of the extracted loadings. We analyze the effect of the harmonized consumer price index (INF), the manufacturing capacity utilization (CU), the unemployment rate (EMP), industrial production (IP) and the real Gross Domestic Product ( $\Delta \mathrm{GDP})$. We evaluate the short and long-run prediction power of the underlying macroeconomic fundamentals for the extracted time series.

We focus on the recent European sovereign-debt crisis. The last few years have challenged all the standard models and have revealed an urge for alternative statistical tools. Our attention is drawn by the bond markets of southern European countries, the epicenter of the recent European sovereign-debt crisis. The DSFM approach is firstly applied as a 
domestic term structure model for each yield curve separately. Yield curve factor models differ with respect to the number of latent factors. Increasing the number of factors leads to better in-sample fit but might weaken the forecasting performance and parsimony of the model. The Nelson-Siegel model assumes three factors whereas its extension proposed

by Svensson (1995) consists of four factors. To this end we investigate the number of factors required to model the yield curve reasonably well, particularly in times of financial turmoil. We select the optimal complexity of the model by statistical criteria. Flexibility of our model allows us to investigate the spatial structure of factors in dependence of additional explanatory variables. In the next step we extend our analysis to the panel data. Modeling the joint term structure of interest rates is a task of extreme importance nowadays, when financial markets have become increasingly globalized. Moreover all the countries share the same currency and monetary policy. They are members of one economic bloc and often grouped together as Euro-zone peripheral states. The joint yield curves are modeled by the panel DSFM (PDSFM) technique.

This paper is structured as follows: in section 2 we describe the data set. The Dynamic Semiparametric Factor Model and the Dynamic Nelson-Siegel model are introduced in section 3. Empirical results and comparison of forecasting performance are provided in sections 4, 5 and 6. In section 7 we summarize the main contribution of the paper.

\section{Data}

In this section, we provide summary statistics on the term structure data. Our primary data sample consists of the monthly end-of-day government zero-coupon bond prices of Greece (GR), Italy (IT), Portugal (PT) and Spain (ES). We focus our analysis on the south-European states starting from the introduction of the European currency, the Euro. Our data set covers the period from January 1999 through to March 2012. Specifically, we consider the interest rates with 11 different times to maturity $X_{t, j}$ ranging from 1 year to 15 years. In Figure 1 we provide a time series plots of Italian and Spanish zero-coupon 
yield curves. The summary statistics for all zero-curves are shown in Tables 7 and 8 . The interest rate data set consists of 160 observations for each country.

To investigate the relation between term structure and macroeconomic activity we study the harmonized consumer price index (INF), capacity utilization (CU), unemployment rate (EMP), industrial production (IP) and the real Gross Domestic Product ( $\Delta$ GDP), observed monthly. This data is from Ecowin.
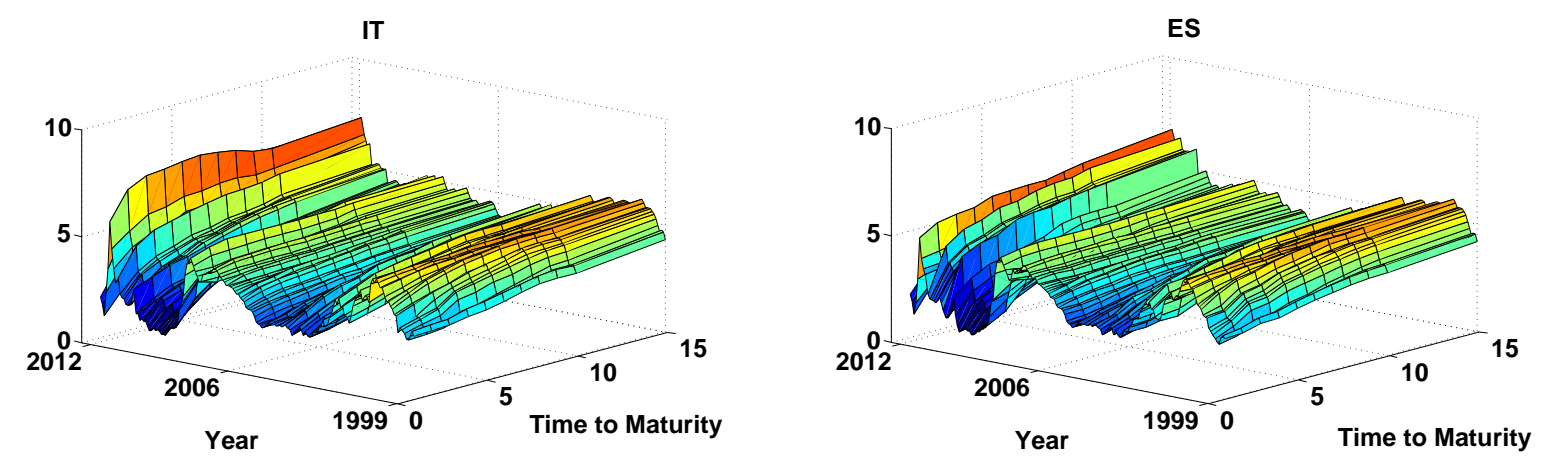

Figure 1: Zero-curves of Italy (left panel) and Spain (right panel) from 1 January 1999 to 31 March 2012

\section{Factor Models}

Factor models describe fluctuations over time in high-dimensional objects by a small set of factors. For analytical tractability and asymptotic properties a sub-additive structure of the model is assumed. In this framework factors are characterized up to scale and rotation transformations and contain the most underlying information. For instance, $Y_{t}=\left(Y_{t, 1}, Y_{t, 2}, \ldots, Y_{t, J}\right) \in \mathbb{R}^{J}$ can be represented as an (orthogonal) $L$-factor model

$$
Y_{t, j}=m_{0, j}+Z_{t, 1} m_{1, j}+\ldots+Z_{L, 1} m_{L, j}+\varepsilon_{t, j}
$$

where $m_{l, j}$ are common factors, $Z_{t, l}$ are factor loadings and $\varepsilon_{t, j}$ are specific errors which explain the residual part. The time evolution of $Y_{t}$ is represented by $Z_{t}, t=1, \ldots, T$. The factors $m_{l}$ may be represented as a function of explanatory variable $X_{t, j}$ In the context of 
yield curve modeling, $Y_{t, j}, j=1, \ldots, J$, denotes the observed term structure of interests rates observed on day $t=1, \ldots, T$. The corresponding time to maturity for $Y_{t, j}$ we denote by $X_{t, j}$. Factor models have gained popularity in the 1990s and the prominent example is the Dynamic Nelson-Siegel model.

\subsection{Dynamic Nelson-Siegel model}

The Nelson-Siegel model fits the yield curve with:

$$
Y_{t, j}=\beta_{0}+\beta_{1}\left\{\frac{1-\exp \left(-\lambda X_{t, j}\right)}{\lambda X_{t, j}}\right\}+\beta_{2}\left\{\frac{1-\exp \left(-\lambda X_{t, j}\right)}{\lambda X_{t, j}}-\exp \left(-\lambda X_{t, j}\right)\right\}+\varepsilon_{t, j}
$$

where $X_{t, j}$ denotes the time to maturity and $\beta_{0}, \beta_{1}, \beta_{2}$ and $\lambda$ are parameters. Parsimonious structure and an ability to provide a good fit to the cross section of yields at a given point in time is a key reason for its popularity. To understand the evolution of the interest rates over time, a dynamic representation was proposed by Diebold and Li (2006), replacing the above parameters with time-varying ones:

$$
\begin{aligned}
Y_{t, j} & =L_{t}+S_{t}\left\{\frac{1-\exp \left(-\lambda X_{t, j}\right)}{\lambda X_{t, j}}\right\}+C_{t}\left\{\frac{1-\exp \left(-\lambda X_{t, j}\right)}{\lambda X_{t, j}}-\exp \left(-\lambda X_{t, j}\right)\right\}+\varepsilon_{t, j} \\
& =Z_{t}^{\top} m\left(X_{t, j}\right)+\varepsilon_{t, j},
\end{aligned}
$$

where $Z_{t}=\left(L_{t}, S_{t}, C_{t}\right)^{\top}$ are the loadings, $m(\cdot)=\left(\mathbf{1}, \frac{1-\exp (-\lambda(\cdot))}{\lambda(\cdot)}, \frac{1-\exp (-\lambda(\cdot))}{\lambda(\cdot)}-\exp (-\lambda(\cdot))\right)$ common factors and $X_{t, j}$ - time to maturity. Note that the decay factor $\lambda_{t}=\lambda$ is tied down to a constant, since time variability of $\lambda_{t}$ has a negligible impact on the model fit and forecasting performance. The Nelson-Siegel factors, with country-specific $\lambda$, stemming from our estimation results, are plotted in Figures 4 and 5 . The yield latent factors $L_{t}$, $S_{t}$ and $C_{t}$ correspond to a level, slope and curvature of the yield curve, respectively. A first order vector autoregressive (VAR) process models the time evolution of a vector of latent factor loadings $Z_{t}$ :

$$
Z_{t}=\mu+\mathcal{A} Z_{t-1}+\eta_{t}
$$

where $\mathcal{A}$ is $(3 \times 3)$ parameter matrix, $\mu$ denotes a $(3 \times 1)$ parameter vector and the $(3 \times 1)$ vector $\eta_{t} \sim \mathrm{N}(0, H), H$ is the conditional variance which is assumed to be diagonal and 
constant over time. The estimation of the Nelson-Siegel model follows a two-step procedure. Fixing the $\lambda$ to predetermined value, the latent factor loadings $Z_{t}$ are estimated separately at each time point using ordinary least squares. Then, in a second step, the estimated factors can be used in a VAR model as represented in equation (5).

\subsection{Dynamic Semiparametric Factor Model}

The DSFM generalizes the factor models given in (1) and (4) to functions of the covariates $X_{t, j}$. Therefore the model takes the form:

$$
Y_{t, j}=\sum_{l=0}^{L} Z_{t, l} m_{l}\left(X_{t, j}\right)+\varepsilon_{t, j}
$$

We assume, that the processes $X_{t, j}, \varepsilon_{t, j}$ and $Z_{t}$ are independent. The number of underlying factors $L$ should be smaller than the number of grid (maturity) points. The functions $m_{l}(\cdot)$ are nonparametric, while the factors $Z_{t, l}$ represent the parametric part. Following Vasicek and Fong (1982), Krivobokova et al. (2006) and Lin (2002), we select a tensor B-spline basis to approximate $m_{l}(\cdot), l=0, \ldots, L$. More formally, the factors $m_{l}(\cdot)$ are represented by $A \psi(\cdot)$, where $A=\left(a_{l, k}\right) \in \mathbb{R}^{(L+1) K}$ denotes a coefficient matrix and $\psi(\cdot)=\left(\psi_{1}, \ldots, \psi_{K}\right)^{\top}$ is a vector of selected basis functions. $K$ stands for the number of knots of the tensor B-splines functions. The number of knots $K$ corresponds to a bandwidth parameter if compared to the kernel smoothing technique of Fengler et al. (2007). Moreover, the functions $m_{l}(\cdot)$ are orthonormalized $\left(\left\|m_{l}(\cdot)\right\|=1\right.$ and $\left\langle m_{l}, m_{k}\right\rangle=0$ for $l \neq k)$ and identifiable up to scale and rotation transformation. The model (6) can be rewritten in terms of $\mathrm{B}$-splines basis and coefficient matrix $A$ as follows

$$
\sum_{l=0}^{L} Z_{t, l} m_{l}\left(X_{t, j}\right)=\sum_{l=0}^{L} Z_{t, l} \sum_{k=1}^{K} a_{l, k} \psi_{k}\left(X_{t, j}\right)=Z_{t}^{\top} A \psi\left(X_{t, j}\right)
$$

Estimation of B-splines coefficient matrix $A$ and low-dimensional factor loadings $Z_{t}$ is

achieved via least squares method. Thus, the estimates $\widehat{A}$ and $\widehat{Z}_{t}$ are given by to following formula

$$
\left(\widehat{Z}_{t}, \widehat{A}\right)=\arg \min _{Z_{t}, A} \sum_{t=1}^{T} \sum_{j=1}^{J}\left\{Y_{t, j}-Z_{t}^{\top} A \psi\left(X_{t, j}\right)\right\}^{2}
$$


The non-linear optimization problem stated in (8) might be solved by a Newton-Raphson iterative algorithm. Some weak conditions on the initial choice of $\left\{\operatorname{vec}\left(A^{(0)}\right), Z_{t}^{(0)}\right\}$ ensure the convergence to the true unknown parameters matrix $A$ and factor loadings $Z_{t}$. It was proved by Park et al. (2009), that the differences between the estimates $\widehat{Z}_{t}$ and the true, unobserved loadings $Z_{t}$ can be asymptotically neglected. This fact allows us to model the dynamics of factor loadings based on estimated time series and therefore study the dynamics of the main, high-dimensional object of interest.

\subsection{Panel DSFM}

Dynamics of the term structure of interest rates can be modeled separately for each country, similarly to other DSFM applications (Härdle et al. (2012), Borak and Weron (2008), Härdle and Trück (2010)). However, following the spirit of Nelson-Siegel model we wish to have common factors for all the analyzed data, and the monetary-specific behavior captured by factor loadings $Z_{t}^{i}$, where $i$ is the country index. Therefore, to analyze all investigated yield curves $i$ simultaneously, we extend (7) to a panel dynamic semiparametric factor model (PDSFM), (Mysiková et al., 2011):

$$
\begin{array}{r}
Y_{t, j}^{i}=m_{0}\left(X_{t, j}\right)+\sum_{l=1}^{L} Z_{t, l}^{i} \bar{m}_{l}\left(X_{t, j}\right)+\varepsilon_{t, j}^{i}, \\
1 \leq j \leq J, 1 \leq t \leq T, 1 \leq i \leq I
\end{array}
$$

$Z_{t, l}^{i}$ is the fixed individual effect for country $i$ on function $\bar{m}_{l}$ at time point $t$.

The PDSFM (9) ensures exactly the same spatial structure of factors among all investigated bond markets. The joint spatial factors are denoted as $\bar{m}_{l}, l=1, \ldots, L$. The term structure differences between the countries and time evolution are captured by their loading time series $Z_{t, l}^{i}$. The model estimation procedure is similar to DSFM estimation, however instead of (8), similarly to common panel data models the sum of squared 
residuals is minimized

$$
S\left(Z^{1}, \ldots, Z^{I}, A\right) \stackrel{\text { def }}{=} \sum_{i=1}^{I} \sum_{t=1}^{T} \sum_{j=1}^{J}\left\{Y_{t, j}^{i}-Z_{t}^{i \top} A \psi\left(X_{t, j}\right)\right\}^{2}
$$

It is worth noting that given $\left(Z^{1}, \ldots, Z^{I}\right)$ or $A$, function $S$ in 10 is quadratic with respect to other variables and therefore the solution can be found by ordinary least squares (OLS) method. To find the solution $\left(\widehat{Z_{t}^{1}}, \ldots, \widehat{Z_{t}^{I}}, \widehat{A}\right)=\arg \min _{Z_{t}^{1}, \ldots, Z_{t}^{I}, A} S\left(Z^{1}, \ldots, Z^{I}, A\right)$ we adopt the following iterative algorithm, similarly to Fengler et al. (2007). (i) Given the initial choice of $\left(Z^{1,(0)}, \ldots, Z^{I,(0)}\right)$ minimize $S\left(Z^{1,(0)}, \ldots, Z^{I,(0)}, A\right)$ with respect to $A$, the explicit solution is given by OLS estimate $A^{(1)}$. (ii) given the $A^{(1)}$ minimize $S\left(Z^{1}, \ldots, Z^{I}, A^{(1)}\right)$ with respect to $\left(Z^{1}, \ldots, Z^{I}\right)$. (iii) iterate (i) and (ii) until convergence. The algorithm runs until only minor changes occur.

\subsection{DSFM $L$ selection}

An important parameter in our model is the number of factors (and corresponding factor loadings) $L$. The choice of $L$ here is based on the explained variance by factors:

$$
E V(L)=1-\frac{\sum_{t=1}^{T} \sum_{j=1}^{J}\left\{Y_{t, j}-\sum_{l=0}^{L} Z_{t, l} m_{l}\left(X_{t, j}\right)\right\}^{2}}{\sum_{t=1}^{T} \sum_{j=1}^{J}\left\{Y_{t, j}-\bar{Y}\right\}^{2}}
$$

In the PDSFM the number of factors is based on the model's explained variance $\overline{E V}$ which is an average of $E V$ of all analyzed countries. We evaluate the model's goodness-of-fit by the root mean squared error (RMSE) criterion,

$$
R M S E=\sqrt{\frac{1}{T J} \sum_{t=1}^{T} \sum_{j=1}^{J}\left\{Y_{t, j}-\sum_{l=0}^{L} Z_{t, l} m_{l}\left(X_{t, j}\right)\right\}^{2}} .
$$

\section{Estimation Results}

To model the yield curve dynamics we implement both DSFM as a domestic model and the panel version PDSFM applied to all states simultaneously. We model first the term 


\begin{tabular}{lcccccc}
\hline \hline \multicolumn{7}{c}{ Separated DSFM } \\
\hline GR & 0.9349 & 0.9872 & 0.9985 & 0.9990 & 0.9995 & 0.9999 \\
IT & 0.7544 & 0.9899 & 0.9952 & 0.9968 & 0.9994 & 0.9995 \\
PT & 0.7936 & 0.9763 & 0.9961 & 0.9987 & 0.9990 & 0.9999 \\
ES & 0.8329 & 0.9874 & 0.9934 & 0.9963 & 0.9978 & 0.9983 \\
& & \multicolumn{7}{c}{ PDSFM } \\
GR & 0.9347 & 0.9782 & 0.9970 & 0.9984 & 0.9998 & 0.9999 \\
IT & 0.8529 & 0.9088 & 0.9857 & 0.9946 & 0.9967 & 0.9982 \\
PT & 0.9108 & 0.9507 & 0.9883 & 0.9957 & 0.9973 & 0.9973 \\
ES & 0.8529 & 0.9088 & 0.9857 & 0.9946 & 0.9968 & 0.9976 \\
$\overline{E V}$ & 0.8999 & 0.9431 & 0.9896 & 0.9963 & 0.9906 & 0.9983 \\
\hline \hline
\end{tabular}

Table 1: Explained variation in percent of the model with different numbers of factors $L$ for the DSFM and PDSFM.

structure as a function of time to maturity solely. Secondly, following Diebold et al. (2006), Ang and Piazzesi (2003) and Hautsch and $\mathrm{Ou}(2012)$ we include macroeconomic variables such as the inflation rate, which may have an impact on the term structure.

\subsection{Domestic Yield Curve Modeling}

In a first step the DSFM was calibrated to the data set comprising the entire period for the term structures domestically (for Greece the period was truncated to 30 June 2011 due to extraordinary high observations). The curve dynamics are modeled in dependence of one regressor: the maturity time. As described in section 2 the members of the yield curve are fixed across time. Thus, we specify the knots as the time to maturity grid and the order of tensor B-splines is set to 1 . The results of the selection of factors $L$ are reported in Table 1. The higher the number of factors, the better is the general fit, 
IT

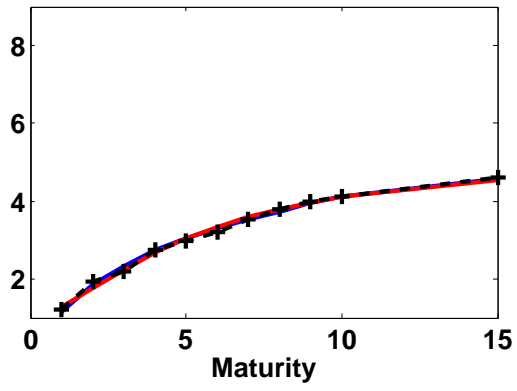

GR

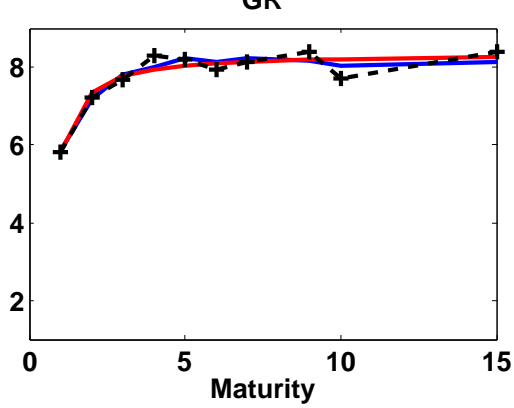

ES

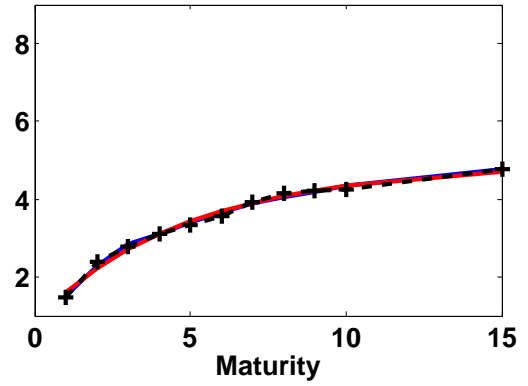

PT

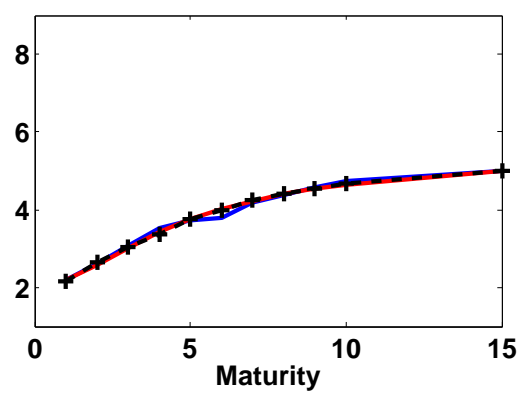

Figure 2: The term structure of interest rates (dotted black) observed on 20100331, DSFM (blue) and the Nelson-Siegel fitted data. We use a DSFM specification with two factors.
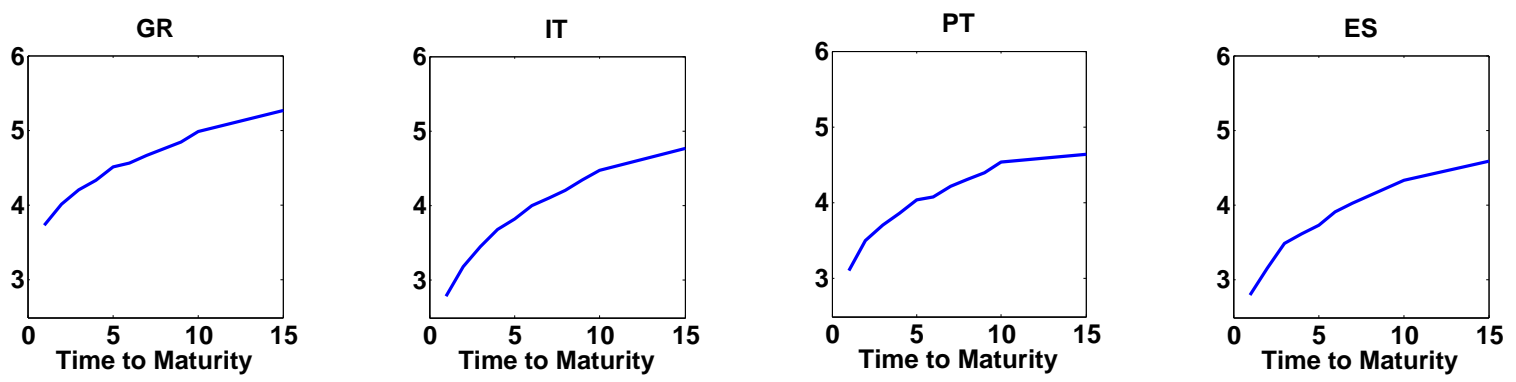

Figure 3: Estimated constant factors $\widehat{M}_{0}$ of the yield curve depending on time to maturity [Years] using the domestic DSFM approach with two factors.

however at the cost of parsimony and robustness of the model. In order to choose the optimal $L$ one proceeds similarly to principal component analysis by selecting the number of factors according to their contribution to the total variation. For domestically modeled curves a two-factor DSFM specification is sufficient. 


\subsubsection{Estimated Factors}
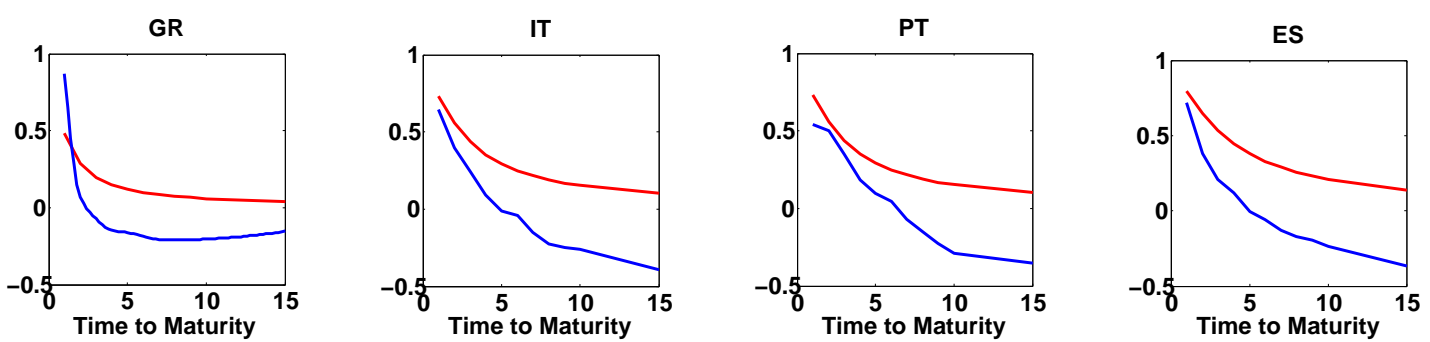

Figure 4: Estimated first factor of the yield curve depending on time to maturity [Years] using the domestic DSFM approach (blue line) with two factors and Nelson-Sigel slope factor (red line) with $\lambda_{G R}=0.049, \lambda_{I T}=0.127, \lambda_{P T}=0.109$ and $\lambda_{E S}=0.174$, respectively.

Figure 4 depicts the estimated first factor. The first factor represents the slope similar to Diebold and Li (2006). We find out that the corresponding Nelson-Siegel slope factor is strikingly different. The shape of the DSFM slope is remarkably similar across countries. The slope is steeper though for short maturities (especially for Greece), more weight is attributed to shorter maturities (1 - 3 years). We attribute it to the economic stagnation that depressed the short rates relative to the benchmark 10 year rate (although overall rates are high). The first factor for Greece is convex and increases slightly for the long maturities. For the remaining countries the slopes are almost identical. The second factor $\widehat{m}_{2}$ across countries is shown in Figure 5 . We observe that they are different from the Nelson-Siegel factors, decrease with the maturity, and exhibit a country-specific peak. The DSFM second factor decreases, but for Portugal it increases with the time to maturity. We also attribute the second factor to the slope of the yield curve.

These findings can be summarized as follows. The nonparametric estimates are similar to the Nelson-Siegel slope factor. There is no curvature factor present for the southern European yield curve dynamics. Their term structure of interest rates and extracted model factors are similar, just as characteristics of their economies are. The impact of the crisis is reflected by the steepness of the first DSFM factor, especially for severely 
struck Greece.
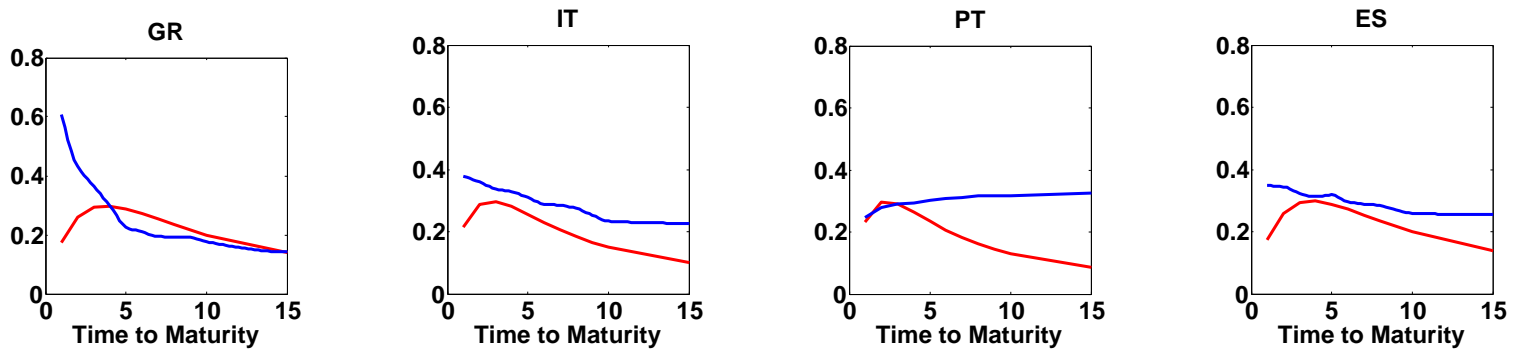

Figure 5: Estimated second factor of the yield curve depending on time to maturity [Years] using domestic the DSFM approach (blue line) with two factors and Nelson-Sigel curvature factor (red line) with $\lambda_{G R}=0.049, \lambda_{I T}=0.127, \lambda_{P T}=0.109$ and $\lambda_{E S}=0.174$.

\subsubsection{Factor Loadings and Yield Curve Dynamics}
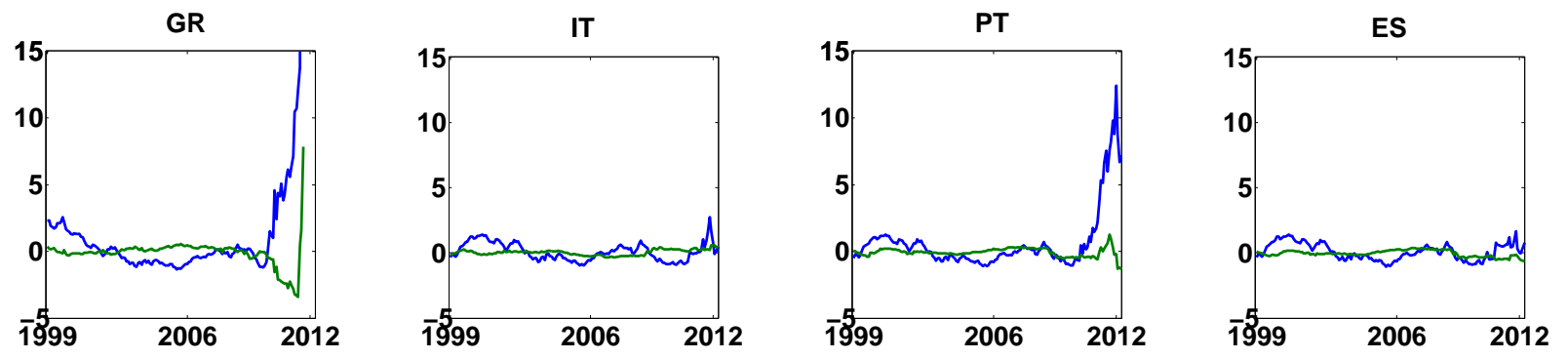

Figure 6: Estimated factor loadings $\widehat{Z}_{t}$ of the yield curve over whole sample using the domestic DSFM with two factors; blue line corresponds to $\widehat{Z}_{t, 1}$, green - $\widehat{Z}_{t, 2}$.

Figure 6 displays the extracted time series $\widehat{Z}_{t}$ for the entire calibration period. The series shows high persistency and unit root $I(1)$ behavior. This observation is in line with the general dynamics of the yield curve which does not change substantially over a small (monthly) time period. In Table 2 we report the stationarity and unit root tests on the first differences of extracted yield curve factor loadings. $\Delta \widehat{Z}_{t} \stackrel{\text { def }}{=} \widehat{Z}_{t}-\widehat{Z}_{t-1}$ are (weak) stationary processes $\left(H_{0}\right.$ is not rejected at significance level $\alpha=5 \%$ ) for all analyzed countries. Based on those diagnostics we consider VAR as a suitable model for dynamics of the extracted $\Delta \widehat{Z}_{t}$. The order $p$ of $\operatorname{VAR}(p)$ is determined by Schwarz and HannanQuinn information criteria (see Table 9). The selected specification will be kept for the 
reminder of the analysis.

\begin{tabular}{rrrrr}
\hline \hline & GR & \multicolumn{1}{c}{ IT } & \multicolumn{1}{c}{ PT } & \multicolumn{1}{c}{ ES } \\
\hline KPSS & 0.427 & 0.060 & 0.075 & 0.062 \\
ADF & -2.492 & -10.901 & -15.454 & -12.334 \\
\hline KPSS & 0.209 & 0.068 & 0.068 & 0.072 \\
ADF & -3.6425 & -13.282 & -11.502 & -12.323 \\
\hline \hline
\end{tabular}

Table 2: KPSS, ADF for estimated first differences of factor loadings $\Delta \widehat{Z}_{t, 1}$ (upper panel) and $\Delta \widehat{Z}_{t, 2}$ (lower panel); (KPSS: $H_{0}$ : weak stationarity, critical values at $0.10,0.05,0.01$ are $0.119,0.146$ and 0.216 ; ADF: $H_{0}$ : unit root, critical values at $0.01,0.05,0.10$ are $-1.61,-1.94$ and -2.58$)$.

\subsubsection{Yield Curve Modeling in Dependence of Further Explanatory Variables}

Dynamic term structure models assume that the time evolution of the yield curve is driven by a (finite) number of latent state variables. A large body of literature studies the economic cause of yield curve factors, see Diebold et al. (2005) and Hautsch and Ou (2012). The explicit relation between term structure and fundamental macroeconomic variables led to the Taylor rule (Taylor, 1992), (Ang and Piazzesi, 2003). This approach provides a convenient way to relate yield curve dynamics with macro data. There are however residual variations in the term structure that are not captured and explained via the inclusion of macro variables. To this end we exploit the DSFM and implement additional regressors. The B-splines knots are an equally spaced grid. The lowest (highest) knot equals a minimum (maximum) of the explanatory variable, corrected by $2 \%$. The results show stable behaviour regarding the choice of the knots.

In Figure 7 we show the estimated first factor $\widehat{m_{1}}(\Xi), \Xi_{t} \stackrel{\text { def }}{=}\left(X_{t, j}, I N F_{t}\right)$ for domestic DSFM with harmonized consumer price index (INF) as a regressor. Firstly, the structure of the factor does not differ much across countries, the impact of the inflation rate is 


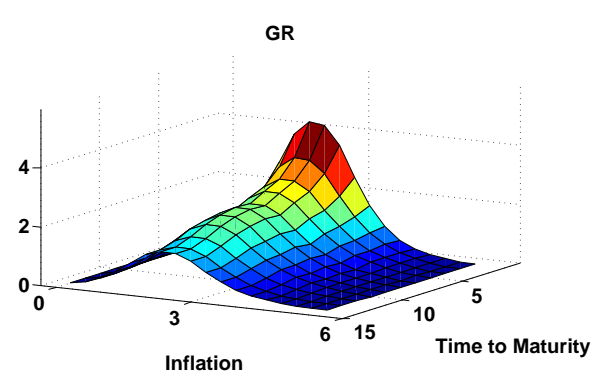

PT

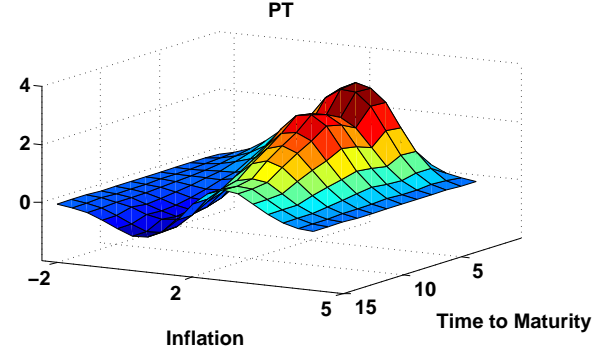

IT

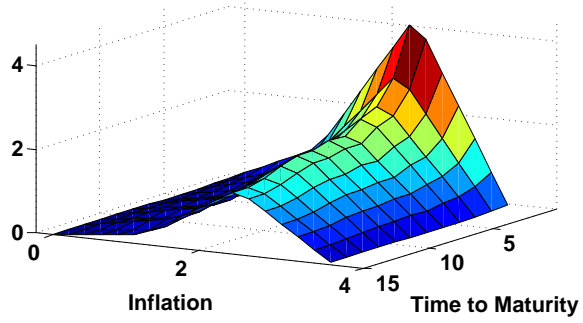

ES

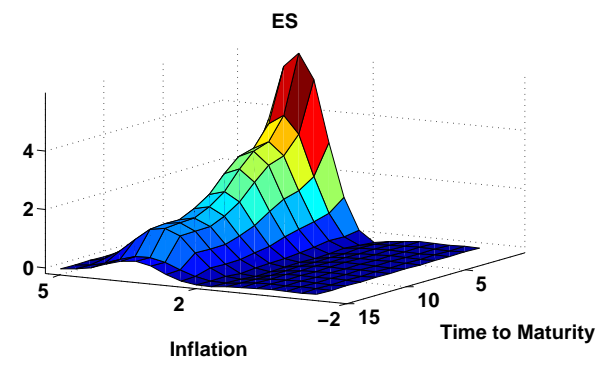

Figure 7: Estimated factors with respect to maturity and inflation rate using domestic DSFM approach with two factors

similar for all states. Secondly, the highest impact is observed on the short rather than on the long rates with a peak at inflation rate around $2 \%$. This central peak may be attributed to the target inflation rate of the central bank. For all countries we observe the decaying impact of the inflation rate for higher maturities; what is in line with expectations. Though the term structure and the harmonised consumer price index are interconnected, it does not improve the model's goodness-of-fit (see Table 3) due to complicity and computational limitations.

\subsection{Panel Yield Curve Modeling}

The domestic interest rate data is demeaned by the country-specific constant factor $\widehat{m}_{0}$. For the PDSFM model selection the one-factor model achieves an explanatory power of $78 \%$, while the inclusion of the second and third factors improves the fit to $94 \%$ and $98 \%$, respectively. The marginal contribution of the fourth factor is relatively small, thus from now on we only consider results for PDSFM specification with $L=3$. The sample period was truncated to 30 June 2011 due to extraordinary high observations. 


\begin{tabular}{rcccc}
\hline \hline & GR & IT & PT & ES \\
\hline NS & 0.5600 & 0.0685 & 0.2009 & 0.0636 \\
DSFM & 0.2886 & 0.0872 & 0.4195 & 0.0695 \\
DSFM(INF) & 0.6813 & 0.1550 & 0.5520 & 0.2110 \\
PDSFM & 0.6810 & 0.1474 & 0.4516 & 0.1434 \\
\hline \hline
\end{tabular}

Table 3: RMSE derived by Nelson-Siegel model (NS), domestic DSFM, DSFM with inflation rate and PDSFM (3 factors) in dependence on time to maturity.
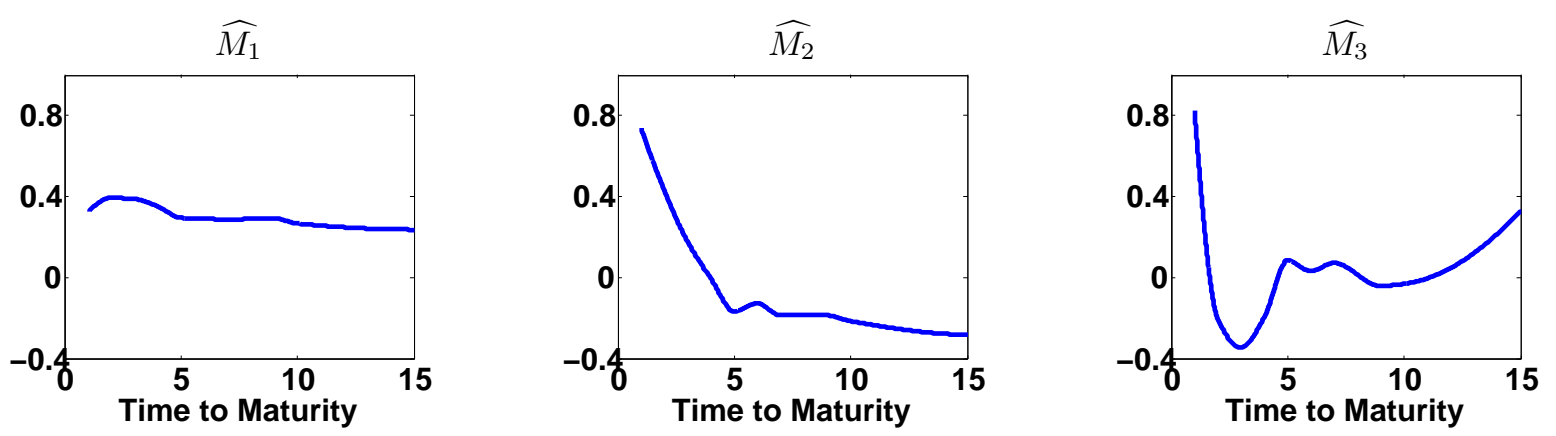

Figure 8: Estimated factors of the yield curve depending on time to maturity [Years] using PDSFM with three factors.

The estimated three factors of PDSFM are depicted in Figure 8 , The first factor is almost constant over all different maturities, thus one can attribute it to the overall level of the yield curve. The slope structure of the second PDSFM factor is noticeably similar to the Nelson-Siegel framework. The third function though does not have a counterpart in the Nelson-Siegel model. It is decreasing for the short maturities and has a bump around the 6 year rate. It is worth noting that the overall performance of the PDSFM is worse than the domestic DSFM approach. One has to include additional factor to explain the same proportion of variation in the data. As expected, the analyzed countries, while sharing some common characteristics, are remarkably different with respect to the bond market (volume, liquidity) and economic policy. Those differences are reflected by the higher order of the model. 
Table 3 presents the RMSE calculated for domestic, panel DSFM approach and the Nelson-Siegel model. One observes that the in-sample fit of the domestic DSFM and the dynamic Nelson-Siegel model are remarkably similar. This stays in favor of the domestic DSFM approach, which captures the yield curve dynamics with just two dynamic factors. Secondly, the PDSFM fit is weaker. Thus, we concentrate on the domestic DSFM technique.

\section{Factors and macroeconomic fundamentals}

In this section we examine the relationship between the factor loadings and the macroeconomic environment. For simplicity of presentation we focus on Italy, which is the third largest bond market in the world and the largest economy among the countries considered. Our analysis is based on five macroeconomic variables: the harmonized consumer price index (INF), the manufacturing capacity utilization $(\mathrm{CU})$, the unemployment rate (EMP), industrial production (IP) and the real Gross Domestic Product ( $\Delta$ GDP). The variable selection is motivated by Diebold et al. (2006) and Hautsch and Ou (2012). The analysis of the contemporaneous correlation between extracted yield curve factor loadings and macroeconomic variables (observed monthly) is done by the regression.

$$
\Delta \widehat{Z}_{t}=C+\beta_{1} I N F_{t}+\beta_{2} C U_{t}+\beta_{3} E M P_{t}+\beta_{4} I P_{t}+\beta_{5} \Delta G D P_{t}+\varepsilon_{t}
$$

The results reported in Table 4 show that the differentiated estimated yield curve first factor loading is driven by the macroeconomic. The explanatory power of macroeconomic variables on the second factor reaches just $6 \%$. We have to note here that both factor loadings and macroeconomic variables are relatively persistent what might cause spurious correlation effects. Thus, before analysis, the time series are detrended. Moreover, as

expected, the Chow test Chow, 1960) for the regression models (for $\Delta \widehat{Z}_{t, 1}$ and $\Delta \widehat{Z}_{t, 2}$ ) before and after the bankruptcy of Lehman Brothers confirmed the structural break in 


\begin{tabular}{cccccccc}
\hline \hline & CONST & INF & CU & EMP & IP & $\Delta$ GDP & $R^{2}$ \\
\hline$\Delta \widehat{Z}_{t, 1}^{I T}$ & -0.018 & $0.8353^{*}$ & -0.018 & -0.147 & $-0.621^{*}$ & $0.732^{*}$ & 0.16 \\
$\Delta \widehat{Z}_{t, 2}^{I T}$ & 0.002 & 0.035 & 0.854 & 0.004 & $-0.202^{*}$ & 0.029 & 0.06 \\
\hline \hline
\end{tabular}

Table 4: Linear regressions of monthly changes factor loadings $\widehat{Z}_{t}$ (separate approach) on (normalized) changes of the harmonized consumer price index (INF), log changes of the capacity utilization $(\mathrm{CU})$, changes of unemployment rate (EMP), changes of industrial production (IP) and the monthly changes in real, log Gross Domestic Product ( $\Delta$ GDP). Significant $(\alpha=0.05)$ estimates with *.

the data at significance level $\alpha=0.05$. The first factor is mainly driven by the inflation rate, real Gross Domestic Product and the industrial production (at a significance level $\alpha=0.05)$. The positive signs of the $I N F$ and $\triangle G D P$ coefficients are economically plausible and in line with the theory. For the second factor, due to the obvious structural break within the analyzed period, the shape of the yield curve can not be explained by the macroeconomic fundamentals.

To investigate the predictability of the DSFM yield factors and their dynamic interdependencies between macroeconomic activity measures, we estimate a VAR(1) model of the yield factors and macroeconomic fundamentals:

$$
F_{t}=\mu+A F_{t-1}+\varepsilon_{t}
$$

where $F_{t} \stackrel{\text { def }}{=}\left(\Delta \widehat{Z}_{t, 1}, \Delta \widehat{Z}_{t, 2}, I N F_{t}, C U_{t}, E M P_{t}, I P_{t}, \Delta G D P_{t}\right)$. The estimation results are shown in Tables 5. We can summarize that the factor loadings primarily depend on their own lags and on those of other factors. Secondly, it is shown that factor loadings are not predictable, based on macroeconomic variables. The coefficients in the estimated $\operatorname{VAR}(1)$ matrices are significantly different than 0 for diagonal elements. We analyze the long-term relations between the yield curve factor loadings and macroeconomic variables by prediction error variance decomposition implied by the VAR estimates. We can summarize the following results. Firstly, in the long perspective, prediction error variances 


\begin{tabular}{rccccccc}
\hline \hline & $Z_{t, 1}$ & $Z_{t, 2}$ & $I N F_{t}$ & $C U_{t}$ & $E M P_{t}$ & $I P_{t}$ & $\Delta G D P_{t}$ \\
\hline$Z_{t-1,1}$ & 0.158 & -0.171 & 0.243 & -0.021 & -0.014 & -0.154 & 0.179 \\
$Z_{t-1,2}$ & 0.161 & -0.076 & -0.049 & -0.137 & -0.002 & -0.242 & 0.034 \\
$I N F_{t-1}$ & 0.029 & -0.107 & 0.306 & -0.034 & 0.072 & 0.130 & 0.170 \\
$C U_{t-1}$ & 0.068 & -0.039 & 0.105 & 0.774 & -0.001 & 0.036 & 0.020 \\
$E M P_{t-1}$ & -0.023 & 0.099 & 0.011 & -0.029 & -0.205 & 0.087 & -0.315 \\
$I P_{t-1}$ & -0.070 & 0.030 & 0.019 & 0.036 & -0.067 & -0.383 & 0.297 \\
$\Delta G D P_{t-1}$ & -0.0323 & 0.123 & -0.003 & 0.0927 & -0.009 & 0.037 & 0.810 \\
\hline \hline
\end{tabular}

Table 5: VAR(1) estimates of monthly IT data set: factor loadings $\widehat{Z}_{t}$ (domestic approach), (normalized) changes of the harmonized consumer price index (INF), log changes of the capacity utilization (CU), changes of unemployment rate (EMP), changes of industrial production (IP) and the monthly changes in real Gross Domestic Product ( $\Delta$ GDP). Sample period $199901-201203$

of factor loadings $\widehat{Z}_{t}$ are not explainable by the macroeconomic fundamentals. The contribution is only up to 10\%, see Figure 13. Hence, in line with Diebold et al. (2006) we report, that yield curve factor loadings are not predicible by the given macroeconomic data set.

\section{$6 \quad$ Forecasting}

\subsection{Setup}

The aim of this section of the paper is to analyze the model's forecasting performance, especially in comparison to the dynamic Nelson-Siegel model as a natural competitor. As in the previous section (5), we focus our analysis on the Italian term structure data. We undertake a short-term forecasting exercise in deriving term structure of interest rates 
monthly, in times of financial distress 2007 - 2012. The models are re-estimated every month exploiting the past information over a whole analyzed period. In accordance with our in-sample analysis reported in the previous section, the domestic DSFM approach with two factors without additional explanatory variables is applied. Secondly, the specified $\operatorname{VAR}(p)$ model for domestic term structure is used to forecast. A natural benchmark is the dynamic Nelson-Siegel model. The forecasting horizon is up to 12 months (observations) ahead. The prediction quality is measured using the root mean squared prediction error (RMSPE) given by

$$
R M S P E=\sqrt{\frac{1}{h J} \sum_{t=1}^{h} \sum_{j=1}^{J}\left\{Y_{t, j}-\sum_{l=0}^{L} \widehat{Z}_{t, l} \widehat{m}_{l}\left(X_{t, j}\right)\right\}^{2}} .
$$

The prediction performance regarding particular maturities $j$ is compared using the following formula

$$
R M S P E(j)=\sqrt{\frac{1}{h} \sum_{t=1}^{h}\left\{Y_{t, j}-\sum_{l=0}^{L} \widehat{Z}_{t, l} \widehat{m}_{l}\left(X_{t, j}\right)\right\}^{2}} .
$$

\subsection{Forecasting Results}

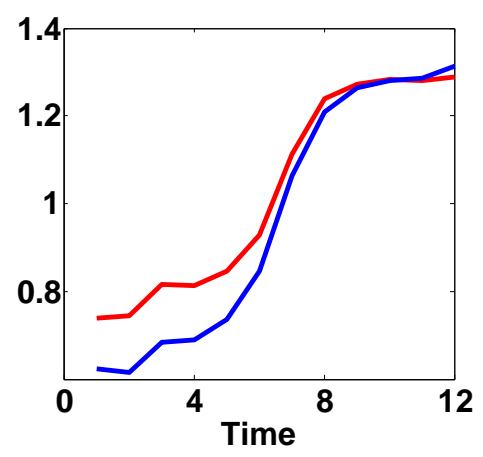

Figure 9: RMSPE derived by the domestic DSFM approach with two factors (blue) and by the dynamic Nelson-Siegel for all forecasting horizons (in months).

The forecasting measures are displayed in Figures 9 and 14 for both the domestic DSFM and the dynamic Nelson-Siegel model and show that the domestic DSFM does better than the dynamic Nelson-Siegel model in a short term forecasting exercise. In the long 
horizon though, the dynamic Nelson-Siegel model is a serious competitor. As expected, the term structure of interest rates can not be well predicted based on its past observations in the long horizon. Secondly, the forecasting performance is better for short and long maturities. The non-parametrically estimated factors and parsimony of the model pay off, especially in times of financial distress. We refer here to the famous rule introduced by Zellner et al. (2002): "Keep it Sophisticatedly Simple" (KISS). The inferior forecasting performance of dynamic Nelson-Siegel model for long maturities might be explained by its general difficulty to fit for longer maturities.

\begin{tabular}{rccccc}
\hline \hline & 1-year & 5-year & 8-year & 10-year & overall \\
\hline DSFM & 0.8600 & 0.6893 & 0.5778 & 0.6575 & 0.6309 \\
NS & 1.2682 & 0.6379 & 0.6564 & 0.7191 & 0.7052 \\
\hline \hline
\end{tabular}

Table 6: Averaged RMSPE over six month forecasting horizon for the domestic DSFM approach and the dynamic Nelson-Siegel model for 1, 5, 8, 10 year maturities and for the entire yield curve.

Table 6 shows the RMSPE averaged over short term forecasting periods for the domestic DSFM approach and the dynamic Nelson-Siegel model. Summarizing one concludes, that the overall prediction performance of the DSFM approach is significantly improved compared to the market benchmark.

\section{Conclusion}

We propose a dynamic semiparametric factor model (DSFM) to model the term structure of interest rates. The DSFM approach was encouraged by the success of factor models. The assumption of parametric, exponential form of the Nelson-Siegel factors is relaxed, they are estimated nonparamatrically. Our framework is flexible and parsimonious. That makes it a useful tool, when standard models fail. The time evolution of south European 

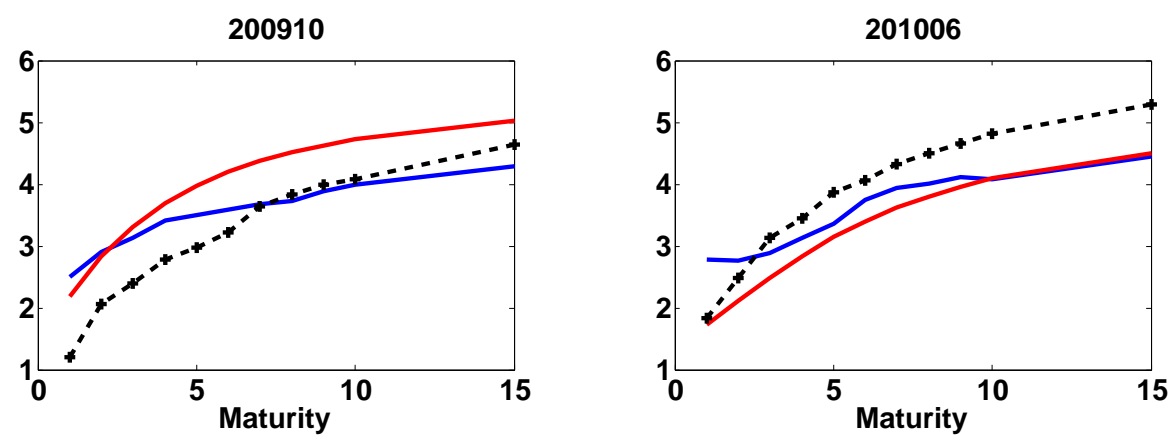

Figure 10: Term structure of interest rates (dotted black) observed on 20091030 (left) and 20100630 (right) for Italy with the DSFM (blue) and the dynamic Nelson-Siegel (red) forecasts.

zero-curves is described by two dynamic factor loadings and one constant function that corresponds to the "averaged" yield curve.

The model is applied to four southern European bond markets over the period January 1997 - March 2012. The focus is on the recent European sovereign-debt crisis. It is shown that two underlying factors can explain more than $95 \%$ of in-sample variations of the domestic zero-curve dynamics. Both factors (ordered in terms of explained variance) correspond to the yield curve's slope. The proposed model achives an explanatory power of $98 \%$, where the inclusion of the third factor does not lead to a significantly better in-sample fit. The extracted factor loadings are unit root processes and reavel high persistency, similar to the zero-curves. The contemporaneous realation with macroeconomic fundamentals is not clearly revealed by the regression analysis due to a structural break in the data. We reported the $R^{2}$ criterion $16 \%$ for the first factor and $6 \%$ for the second one. Though it is known that yield curves are driven by explanatory variables i.e. the inflation rate, those variables do not improve the model's goodness-of-fit. 


\section{References}

Ang, A. and Piazzesi, M. (2003). A No-Arbitrage Vector Autoregression of Term Structure Dynamics with Macroeconomic and Latent Variables, Journal of Monetary Economics 50: $745-787$.

Borak, S. and Weron, R. (2008). A Semiparametric Factor Model for Electricity Forward Curve Dynamics, Journal of Energy Markets 1(3).

Bowsher, C. G. and Meeks, R. (2008). The dynamics of economic functions: Modeling and forecasting the yield curve, Journal of the American Statistical Association 103(484): 1419-1437.

Brüggemann, R., Härdle, W., Mungo, J. and Trenkler, C. (2008). VAR Modelling for Dynamic Semiparametric Factors of Volatility Strings, Journal of Financial Econometrics 6(3): 361-381.

Chow, G. C. (1960). Tests of equality between sets of coefficients in two linear regressions, Econometrica 28(3): pp. 591-605.

Christensen, J., Diebold, F. and Rudebusch, G. (2009). An Arbitrage-Free Generalized Nelson-Siegel Term Structure Model, The Econometrics Journal 12: 33-64.

Coroneo, L., Nyhlon, K. and Vidova-Koleva, R. (2008). How arbitrage free is NelsonSiegel Model?, Working Paper 874, European Central Bank.

Diebold, F., Piazzesi, M. and Rudebusch, G. (2005). Modeling Bond Yields in Finance and Macroeconomics, American Economic Review 95: 415-420.

Diebold, F., Rudebusch, G. and Aruoba, S. (2006). The Macroeconomy and Yield Curve: a Dynamic Latent Factor Approach, Journal of Econometrics 131: 309-338.

Diebold, F. X. and Li, C. (2006). Forecasting the Term Structure of Government Bond Yields, Journal of Econometrics 130: 337-364. 
Fengler, M. R., Härdle, W. and Mammen, E. (2007). A Dynamic Semiparametric Factor Model for Implied Volatility String Dynamics, Journal of Financial Econometrics 5: $189-218$.

Gürkaynak, R. S., Sack, B. and Wright, J. H. (2010). The TIPS Yield Curve and Inflation Compensation, American Economic Association 2: 70-92.

Härdle, W., Hautsch, N. and Mihoci, A. (2012). Modelling and Forecasting Liquidity Supply Using Semiparametric Factor Dynamics, Journal of Empirical Finance. DOI: 10.1016/j.jempfin.2012.04.002, SFB 649 DP 2009-44.

Härdle, W. and Trück, S. (2010). The Dynamics of Hourly Electricity Prices, Applied Financial Economic, submitted. SFB 649 DP 2009-013.

Hautsch, N. and Ou, Y. (2012). Yield Curve Factors, Term Structure Volatility, and Bond Risk Premia, Journal of Banking and Finance. Submitted, SFB 649 DP 2008-53.

Heath, D., Jarrow, R. and Morton, A. (1992). Bond Pricing and the Term Structure of Interest Rates: a New Methodology for Contingent Claims Valuation, Econometrica 60: $77-105$.

Hull, J. and White, A. (1990). Pricing Interest Rate Derivative Decurities, Review of Financial Studies 3(4): 573-592.

Krivobokova, T., Kauermann, G. and Archontakis, T. (2006). Estimating the Term Structure of Interest Rates Using Penalized Splines, Statistical Papers 47: 443-459.

Lin, B. H. (2002). Fitting Term Structure of Interest Rates Using B-splines: the Case of Taiwanese Government Bonds, Applied Financial Economics 1: 57-75.

Longstaff, F. A. and Schwartz, E. S. (1992). Interest rate volatility and the term structure: A two-factor general equilibrium model, Journal of Finance 47(4): 1259-82.

Mysiková, A., Song, S., Majer, P., Mohr, P., Heekeren, H. and Härdle, W. (2011). Risk Patterns and Correlated Brain Activities. Multidimensional statistical analysis 
of fMRI data with application to risk patterns, Annals of Applied Statistics . Submitted, manuscript ID: AOAS1208-002, SFB 649 DP 2011-85.

Park, B., Mammen, E., Härdle, W. and Borak, S. (2009). Time Series Modelling With Semiparametric Factor Dynamics, Journal of the American Statistical Association 104(485): 284-298.

Ramsay, J. and Silverman, B. (1997). Functional Data Analysis, Springer series in statistics.

Svensson, L. E. O. (1995). Estimating Forward Interest Rates with the Extended NelsonSiegel Method, Quarterly Review Sveriges Riksbank 3: 13-26.

Taylor, J. B. (1992). Discretion versus Policy Rules in Practice, Carnegie-Rochester Conference Series on Public Policy 39: 195-214.

Vasicek, O. and Fong, H. G. (1982). Term Structure Modeling Using Exponential Splines, Journal of Finance 37: 339-356.

Zellner, A., Keuzenkamp, H. A. and McAleer, M. (2002). Simplicity, Inference and Modelling, Cambridge University Press. 


\section{Appendix}

\begin{tabular}{|c|c|c|c|c|c|}
\hline & Mean & Median & $\mathrm{SD}$ & Skewness & Kurtosis \\
\hline \multicolumn{6}{|l|}{ Greece } \\
\hline \multicolumn{6}{|l|}{ Levels } \\
\hline 1-year & 4.6969 & 3.6245 & 4.1007 & 4.7708 & 37.7046 \\
\hline 3-year & 5.3384 & 4.1219 & 4.2326 & 3.1321 & 13.9549 \\
\hline 5 -year & 5.3026 & 4.3569 & 2.9831 & 2.4804 & 8.7310 \\
\hline 10-year & 5.7074 & 5.1632 & 2.0136 & 2.0951 & 7.4392 \\
\hline \multicolumn{6}{|c|}{ Changes in } \\
\hline 1-year & -0.0009 & 0.0155 & 1.9473 & -8.4143 & 89.4413 \\
\hline 3-year & -0.0008 & 0.0265 & 1.0061 & -2.9892 & 24.7871 \\
\hline 5-year & -0.0002 & 0.0175 & 0.6759 & -2.3611 & 17.9979 \\
\hline 10-year & -0.0001 & 0.0012 & 0.3936 & -2.3989 & 13.6143 \\
\hline \multicolumn{6}{|l|}{ Italy } \\
\hline \multicolumn{6}{|l|}{ Levels } \\
\hline 1-year & 2.8736 & 2.7843 & 1.1719 & 0.0523 & 2.1771 \\
\hline 3 -year & 3.5394 & 3.4493 & 0.9836 & 0.4591 & 3.0203 \\
\hline 5-year & 3.9361 & 3.8228 & 0.8649 & 0.6655 & 3.5370 \\
\hline 10-year & 4.6039 & 4.4694 & 0.6801 & 0.5987 & 3.4534 \\
\hline \multicolumn{6}{|c|}{ Changes in } \\
\hline 1-year & 0.0066 & -0.0164 & 0.3646 & 1.3801 & 12.7428 \\
\hline 3-year & -0.0048 & -0.0056 & 0.3826 & 0.1485 & 9.5065 \\
\hline 5-year & -0.0085 & 0.0062 & 0.3453 & -0.0403 & 8.8564 \\
\hline 10-year & -0.0101 & 0.0151 & 0.2476 & -0.0234 & 7.2980 \\
\hline
\end{tabular}

Table 7: Statistical summary of the level and change series of 1,3,5,10-year zero-coupon bond yields. The sample of Greek data is from January, 1999 to June 2011; the sample for Italy is from January, 1999 to March 2012; SD denotes Standard Deviation. 


\begin{tabular}{|c|c|c|c|c|c|}
\hline & Mean & Median & $\mathrm{SD}$ & Skewness & Kurtosis \\
\hline \multicolumn{6}{|c|}{ Portugal } \\
\hline \multicolumn{6}{|l|}{ Levels } \\
\hline 1-year & 3.5353 & 3.1029 & 2.1676 & 2.3915 & 10.3401 \\
\hline 3-year & 4.5377 & 3.7105 & 3.3085 & 2.9769 & 11.9225 \\
\hline 5 -year & 4.8341 & 4.0366 & 2.9935 & 2.9600 & 11.7316 \\
\hline 10-year & 5.2021 & 4.5398 & 2.1242 & 2.6980 & 10.3645 \\
\hline \multicolumn{6}{|c|}{ Changes in } \\
\hline 1-year & -0.0039 & -0.0136 & 0.7707 & 3.5002 & 28.6326 \\
\hline 3-year & -0.0679 & -0.0120 & 0.9918 & 0.2136 & 22.5985 \\
\hline 5 -year & -0.0669 & 0.0075 & 0.8773 & -0.4221 & 20.3009 \\
\hline 10-year & -0.0512 & 0.0002 & 0.4856 & -0.6836 & 15.7143 \\
\hline \multicolumn{6}{|l|}{ Spain } \\
\hline \multicolumn{6}{|l|}{ Levels } \\
\hline 1-year & 2.8556 & 2.8062 & 1.1540 & 0.0056 & 2.0978 \\
\hline 3-year & 3.4844 & 3.4875 & 0.8802 & 0.1938 & 2.0900 \\
\hline 5-year & 3.8672 & 3.7370 & 0.7923 & 0.2639 & 2.0215 \\
\hline 10-year & 4.4929 & 4.3304 & 0.6960 & 0.2219 & 2.1219 \\
\hline \multicolumn{6}{|c|}{ Changes in } \\
\hline 1-year & 0.0049 & -0.0300 & 0.3226 & 1.6994 & 12.8158 \\
\hline 3-year & -0.0050 & 0.0048 & 0.3662 & 0.6379 & 12.3061 \\
\hline 5 -year & -0.0087 & 0.0150 & 0.3364 & 0.0259 & 11.7166 \\
\hline 10-year & -0.0124 & 0.0074 & 0.2611 & 0.0387 & 9.4403 \\
\hline
\end{tabular}

Table 8: Statistical summary of the level and change series of 1,3,5,10-year zero-coupon bond yields. The sample is from January, 1999 to March 2012. 

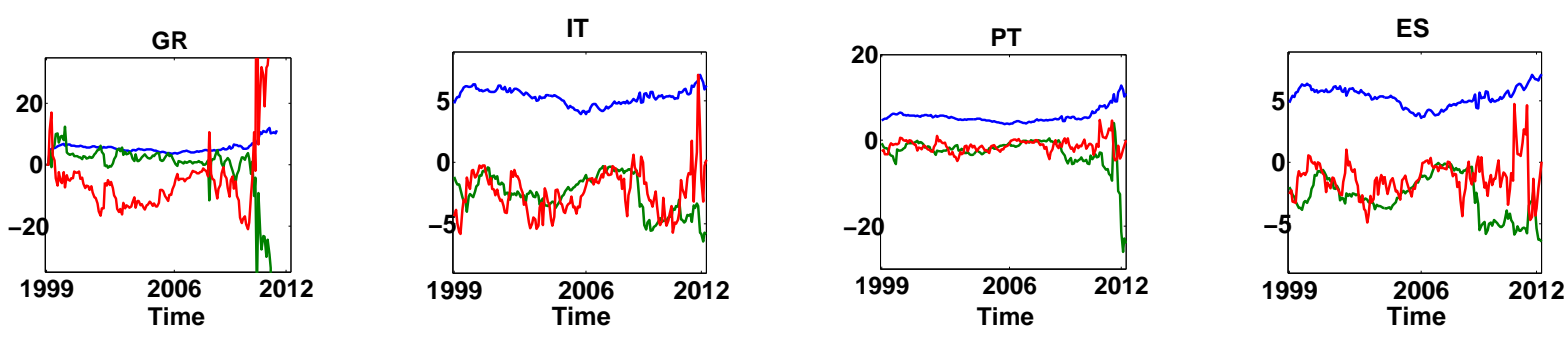

Figure 11: Estimated Nelson-Siegel factors: $L_{t}$ level (blue), $S_{t}$ slope (green) and $C_{t}$ curvature (red) for Greece, Italy, Portugal and Spain with with $\lambda_{G R}=0.049, \lambda_{I T}=0.127$, $\lambda_{P T}=0.109$ and $\lambda_{E S}=0.174$, respectively.
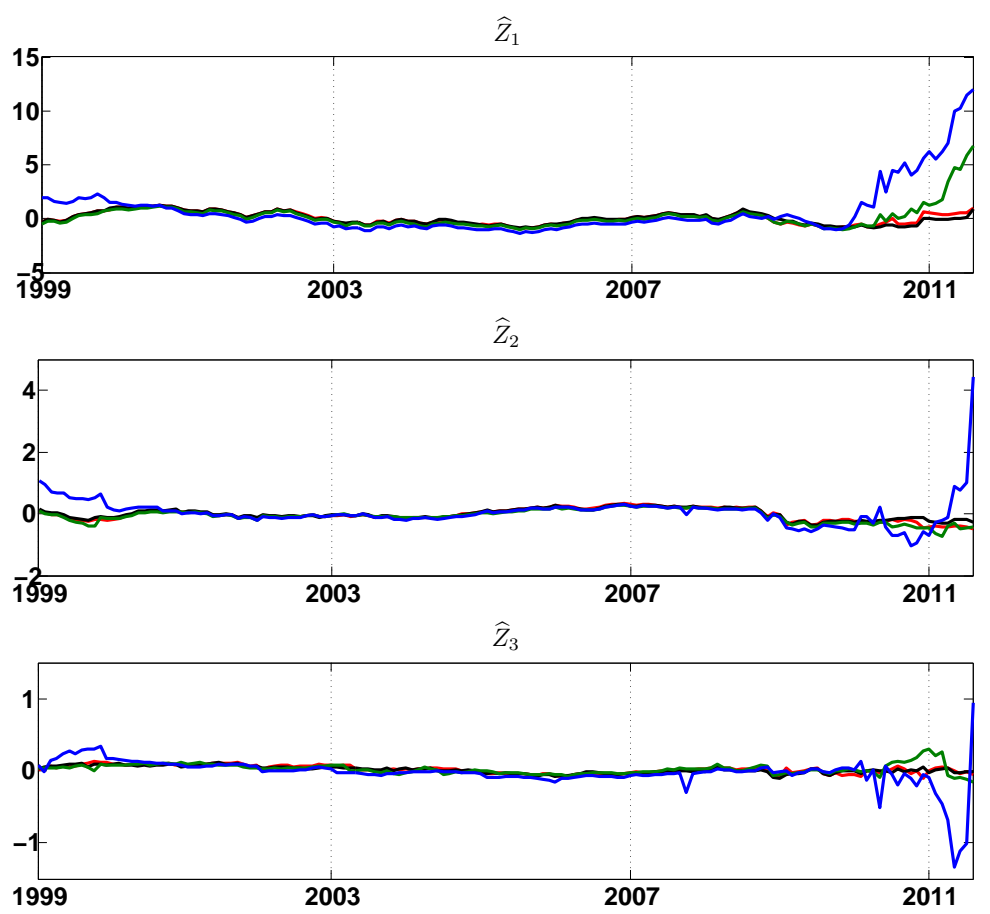

Figure 12: Estimated factor loadings $\widehat{Z}_{t, 1}$ (top), $\widehat{Z}_{t, 2}$ (middle) and $\widehat{Z}_{t, 2}$ (bottom) of the yield curve over the whole sample using PDSFM with three factors; blue lines corresponds to $\widehat{Z}_{t}^{G R}$, red - $\widehat{Z}_{t}^{E S}$, green - $\widehat{Z}_{t}^{P T}$ and black - $\widehat{Z}_{t}^{I T}$.

\begin{tabular}{rcccc}
\hline \hline$p$ & 1 & 2 & 3 & 4 \\
\hline $\mathrm{SC}$ & -8.04 & -7.98 & -7.90 & -7.83 \\
$\mathrm{HQ}$ & -8.11 & -8.10 & -8.07 & -8.04 \\
\hline \hline
\end{tabular}

Table 9: Hannan-Quinn and Schwarz information criteria for the $\operatorname{VAR}(p)$ model for Italy. 

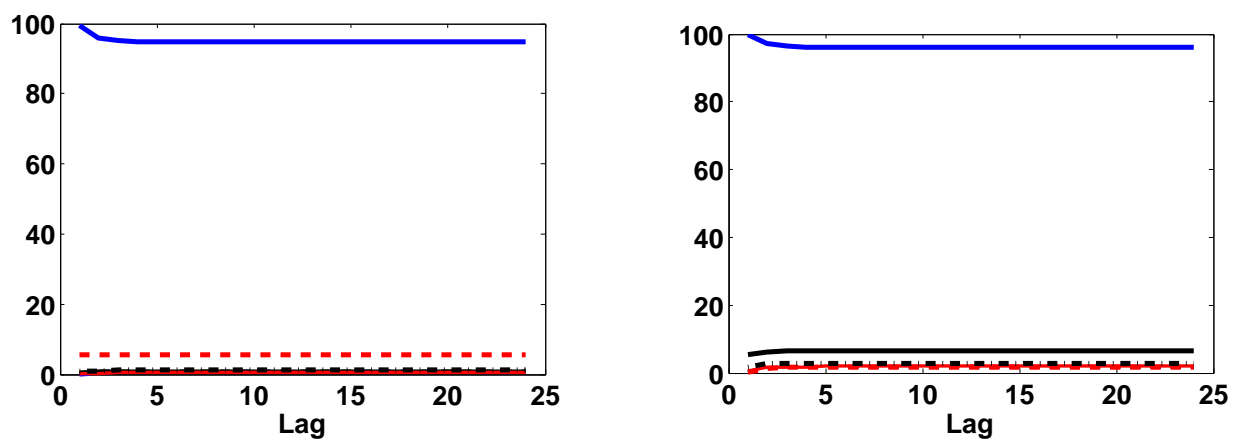

Figure 13: Prediction error decomposition of the first factor loadings $\widehat{Z}_{t, 1}$ (left panel) and $\widehat{Z}_{t, 2}$ (right panel). Based on a $\operatorname{VAR}(1)$ model of yield factors and macro factors using a Cholesky decomposition of the covariance. Extracted factor loadings and macroeconomic fundamentals for Italy.
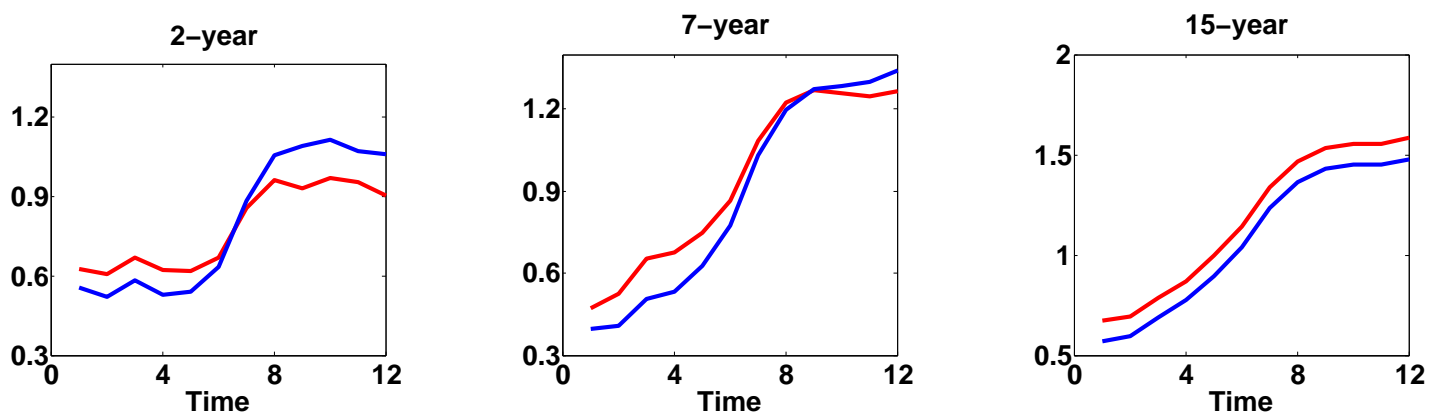

Figure 14: Root mean squared prediction errors $(R M S P E(j))$ derived by the domestic DSFM approach with two factors (blue) and by the dynamic Nelson-Siegel for all forecasting horizons (in months) for maturities: 2 years (1st column), 7 years (2nd) and 15 years (3rd). 


\section{SFB 649 Discussion Paper Series 2012}

For a complete list of Discussion Papers published by the SFB 649, please visit http://sfb649.wiwi.hu-berlin.de.

001 "HMM in dynamic HAC models" by Wolfgang Karl Härdle, Ostap Okhrin and Weining Wang, January 2012.

002 "Dynamic Activity Analysis Model Based Win-Win Development Forecasting Under the Environmental Regulation in China" by Shiyi Chen and Wolfgang Karl Härdle, January 2012.

003 "A Donsker Theorem for Lévy Measures" by Richard Nickl and Markus Reiß, January 2012.

004 "Computational Statistics (Journal)" by Wolfgang Karl Härdle, Yuichi Mori and Jürgen Symanzik, January 2012.

005 "Implementing quotas in university admissions: An experimental analysis" by Sebastian Braun, Nadja Dwenger, Dorothea Kübler and Alexander Westkamp, January 2012.

006 "Quantile Regression in Risk Calibration" by Shih-Kang Chao, Wolfgang Karl Härdle and Weining Wang, January 2012.

007 "Total Work and Gender: Facts and Possible Explanations" by Michael Burda, Daniel S. Hamermesh and Philippe Weil, February 2012.

008 "Does Basel II Pillar 3 Risk Exposure Data help to Identify Risky Banks?" by Ralf Sabiwalsky, February 2012.

009 "Comparability Effects of Mandatory IFRS Adoption" by Stefano Cascino and Joachim Gassen, February 2012.

010 "Fair Value Reclassifications of Financial Assets during the Financial Crisis" by Jannis Bischof, Ulf Brüggemann and Holger Daske, February 2012.

011 "Intended and unintended consequences of mandatory IFRS adoption: A review of extant evidence and suggestions for future research" by Ulf Brüggemann, Jörg-Markus Hitz and Thorsten Sellhorn, February 2012.

012 "Confidence sets in nonparametric calibration of exponential Lévy models" by Jakob Söhl, February 2012.

013 "The Polarization of Employment in German Local Labor Markets" by Charlotte Senftleben and Hanna Wielandt, February 2012.

014 "On the Dark Side of the Market: Identifying and Analyzing Hidden Order Placements" by Nikolaus Hautsch and Ruihong Huang, February 2012.

015 "Existence and Uniqueness of Perturbation Solutions to DSGE Models" by Hong Lan and Alexander Meyer-Gohde, February 2012.

016 "Nonparametric adaptive estimation of linear functionals for low frequency observed Lévy processes" by Johanna Kappus, February 2012.

017 "Option calibration of exponential Lévy models: Implementation and empirical results" by Jakob Söhl und Mathias Trabs, February 2012.

018 "Managerial Overconfidence and Corporate Risk Management" by Tim R. Adam, Chitru S. Fernando and Evgenia Golubeva, February 2012.

019 "Why Do Firms Engage in Selective Hedging?" by Tim R. Adam, Chitru S. Fernando and Jesus M. Salas, February 2012.

020 "A Slab in the Face: Building Quality and Neighborhood Effects" by Rainer Schulz and Martin Wersing, February 2012.

021 "A Strategy Perspective on the Performance Relevance of the CFO" by Andreas Venus and Andreas Engelen, February 2012.

022 "Assessing the Anchoring of Inflation Expectations" by Till Strohsal and Lars Winkelmann, February 2012.

\section{SFB 649, Spandauer Straße 1, D-10178 Berlin http:/ / sfb649.wiwi.hu-berlin.de}

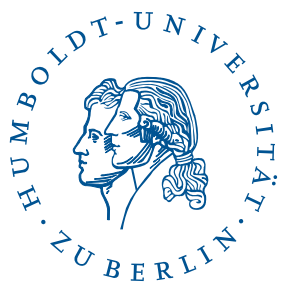




\title{
SFB 649 Discussion Paper Series 2012
}

For a complete list of Discussion Papers published by the SFB 649, please visit http://sfb649.wiwi.hu-berlin.de.

023 "Hidden Liquidity: Determinants and Impact" by Gökhan Cebiroglu and Ulrich Horst, March 2012.

024 "Bye Bye, G.I. - The Impact of the U.S. Military Drawdown on Local German Labor Markets" by Jan Peter aus dem Moore and Alexandra Spitz-Oener, March 2012.

025 "Is socially responsible investing just screening? Evidence from mutual funds" by Markus Hirschberger, Ralph E. Steuer, Sebastian Utz and Maximilian Wimmer, March 2012.

026 "Explaining regional unemployment differences in Germany: a spatial panel data analysis" by Franziska Lottmann, March 2012.

027 "Forecast based Pricing of Weather Derivatives" by Wolfgang Karl Härdle, Brenda López-Cabrera and Matthias Ritter, March 2012.

028 "Does umbrella branding really work? Investigating cross-category brand loyalty" by Nadja Silberhorn and Lutz Hildebrandt, April 2012.

029 "Statistical Modelling of Temperature Risk" by Zografia Anastasiadou, and Brenda López-Cabrera, April 2012.

030 "Support Vector Machines with Evolutionary Feature Selection for Default Prediction" by Wolfgang Karl Härdle, Dedy Dwi Prastyo and Christian Hafner, April 2012.

031 "Local Adaptive Multiplicative Error Models for High-Frequency Forecasts" by Wolfgang Karl Härdle, Nikolaus Hautsch and Andrija Mihoci, April 2012.

032 "Copula Dynamics in CDOs." by Barbara Choroś-Tomczyk, Wolfgang Karl Härdle and Ludger Overbeck, May 2012.

033 "Simultaneous Statistical Inference in Dynamic Factor Models" by Thorsten Dickhaus, May 2012.

034 "Realized Copula" by Matthias R. Fengler and Ostap Okhrin, Mai 2012.

035 "Correlated Trades and Herd Behavior in the Stock Market" by Simon Jurkatis, Stephanie Kremer and Dieter Nautz, May 2012

036 "Hierarchical Archimedean Copulae: The HAC Package" by Ostap Okhrin and Alexander Ristig, May 2012.

037 "Do Japanese Stock Prices Reflect Macro Fundamentals?" by Wenjuan Chen and Anton Velinov, May 2012.

038 "The Aging Investor: Insights from Neuroeconomics" by Peter N. C. Mohr and Hauke R. Heekeren, May 2012.

039 "Volatility of price indices for heterogeneous goods" by Fabian Y.R.P. Bocart and Christian M. Hafner, May 2012.

040 "Location, location, location: Extracting location value from house prices" by Jens Kolbe, Rainer Schulz, Martin Wersing and Axel Werwatz, May 2012.

041 "Multiple point hypothesis test problems and effective numbers of tests" by Thorsten Dickhaus and Jens Stange, June 2012

042 "Generated Covariates in Nonparametric Estimation: A Short Review." by Enno Mammen, Christoph Rothe, and Melanie Schienle, June 2012.

043 "The Signal of Volatility" by Till Strohsal and Enzo Weber, June 2012.

044 "Copula-Based Dynamic Conditional Correlation Multiplicative Error Processes" by Taras Bodnar and Nikolaus Hautsch, July 2012

\author{
SFB 649, Spandauer Straße 1, D-10178 Berlin \\ http:/ / sfb649.wiwi.hu-berlin.de
}




\section{SFB 649 Discussion Paper Series 2012}

For a complete list of Discussion Papers published by the SFB 649, please visit http://sfb649.wiwi.hu-berlin.de.

045 "Additive Models: Extensions and Related Models." by Enno Mammen, Byeong U. Park and Melanie Schienle, July 2012.

046 "A uniform central limit theorem and efficiency for deconvolution estimators" by Jakob Söhl and Mathias Trabs, July 2012

047 "Nonparametric Kernel Density Estimation Near the Boundary" by Peter Malec and Melanie Schienle, August 2012

048 "Yield Curve Modeling and Forecasting using Semiparametric Factor Dynamics" by Wolfgang Karl Härdle and Piotr Majer, August 2012 